\title{
Dislocation structure of a dry-steam pipe steel as a function of long-term service
}

\author{
T. Ungár ${ }^{1 *}$, G. Gémes ${ }^{2}$, L. Balogh ${ }^{1,3}$ \\ ${ }^{1}$ Department of Materials Physics, Eötvös University Budapest, Hungary \\ ${ }^{2} T \ddot{U} V$ Rheinland Intercert Kft., H-1132 Budapest, Hungary \\ ${ }^{3}$ Department of Mechanical and Materials Engineering, Queen's University, Kingston, ON K7L 3N6, Canada
}

Received 30 March 2015, received in revised form 30 March 2015, accepted 21 May 2015

\begin{abstract}
The dislocation structure in dry-steam pipe steel has been determined by X-ray line profile analysis as the function of long-term service from the initial state up to $220.384 \mathrm{~h}$. The specimens are taken from a Hungarian fossil fuelled power plant where the dry-steam pipe has been operating at about $540{ }^{\circ} \mathrm{C}$ at 165 bar. X-ray diffraction patterns were taken in a conventional $\theta-2 \theta$ powder diffractometer and in a special high resolution double crystal diffractometer dedicated for line profile analysis. The $\theta-2 \theta$ powder diffractograms reveal narrower peaks in the low angle range than the peaks of the NIST SRM-660a LaB 6 standard specimen. In the high angle range the peaks of the steel specimens are broader than the standard peaks indicating the presence of microstrain. Dislocation densities were evaluated in individual grains by using the convolutional multiple whole profile fitting procedure and were obtained to vary between $10^{13}$ and $10^{14} \mathrm{~m}^{-2}$, decreasing towards the end of the service life of the tube. Data from metallographic micrographs are in good correlation with X-ray diffraction results.
\end{abstract}

K e y words: dislocation density, intergranular stresses, life time of dry-steam pipe steel, high resolution X-ray diffraction

\section{Introduction}

About two third of the electric power in Hungary is still generated in fossil fuelled power plants installed some 20 to 30 years ago. The dry-steam pipes system, one of the key parts of these power plants, is made from the 12H1MF type low-alloy creep-resistant steel fabricated in the former Soviet Union. The $R_{\mathrm{P}, 0.2}$ flow stress values of the creep tested materials are shown in the Larson-Miller type diagram in Fig. 1, where the Larson-Miller parameter values are: $p=T(\lg t+$ $c), T$ is the working temperature in $\mathrm{K}, t$ is the test period in hours and $c$ is a material constant, in the present case $c=20( \pm 2)$. The figure indicates that the $R_{\mathrm{P}, 0.2}$ flow stress values provided by the delivering company are considerably higher than the values measured in two independent testing laboratories, one in the former East-German Democratic Republic (GDR) and one in the Hungarian testing laboratory "EROKKAR". It is noted that the data obtained in the independent German and Hungarian laboratories are in close correlation. For safety and reliability continuous inspection of the critical components in the power plant is carried out by mechanical monitoring of the macroscopic size of the hot pipe sections [1] or by metallographic sampling of the microstructure of materials [2-4]. In a previous paper we determined the standard deviation of intergranular strains and stresses in curved sections of a dry-steam pipe as a function of operation period up to $220.384 \mathrm{~h}$ [5]. It was shown that the values are close to zero in the initial state in correlation with the stress releasing heat treatments applied to the dry-steam pipe section prior to installation. The same test revealed large values within the range between 50 to $100 \mathrm{MPa}$ after an operation period of $154.530 \mathrm{~h}$. Finally, the standard deviation of intergranular strains decreased almost to zero after a service period of $220.384 \mathrm{~h}$. It was shown that the intergranular stresses built up during service because of the elastic anisotropy of steel. Grains oriented

*Corresponding author: tel./fax: +3613722801/11; e-mail address: ungar@ludens.elte.hu 


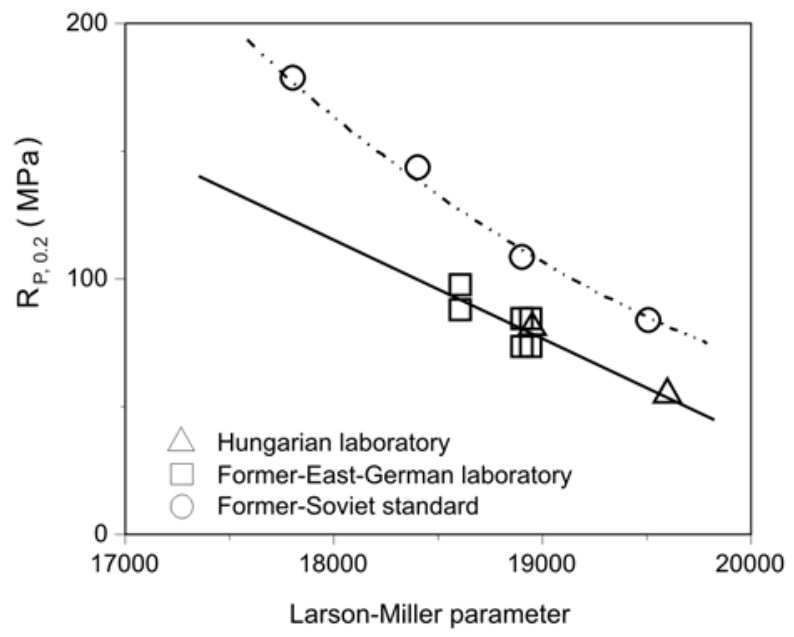

Fig. 1. Larson-Miller type diagram of the $R_{\mathrm{P}, 0.2}$ flow stress values of the creep tested materials.

with soft or hard orientations parallel to the main stress component under pressure, are back-strained to different levels during unloading. The final decrease of intergranular stresses after long terms service was explained by the catastrophic deterioration of grain boundaries incapable to bear the intergranular stresses during the cooling and unloading procedure [5]. In the present work the method of high resolution X-ray line profile analysis is used to determine the change of the dislocation density in the same materials. The correlation between intergranular stresses, dislocation densities and metallographic results is discussed in terms of long term service in dry-steam pipe steel materials.

\section{Experimental}

\subsection{X-ray diffraction experiments}

The steel specimens investigated here have an average grain size of about $30 \mu \mathrm{m}$ and low dislocation density in the range of $10^{13}$ to $10^{14} \mathrm{~m}^{-2}$. In accordance with these microstructure parameter values the X-ray line broadening of these specimens is small. For that reason two different X-ray diffractometers are used to measure the diffraction patterns. The overall diffraction pattern is determined in conventional $\theta-2 \theta$ Philips X'pert powder diffractometer using $\mathrm{Cu} \mathrm{K} \alpha$ radiation and pyrolitic graphite secondary monochromator. The instrumental pattern was measured by using a NIST SRM-660a $\mathrm{LaB}_{6}$ peak profile standard material. Peak broadening of the steel specimens turned out to be very small. The FWHM of the $\mathrm{K} \alpha_{1}$ component can be evaluated readily and is shown in $1 / \mathrm{nm}$ scale in a Williamson-Hall type plot in Fig. 2. The 200 peak of the $\mathrm{LaB}_{6}$ specimen is considerably broader than the 110 peak of the steel specimen. At higher angles

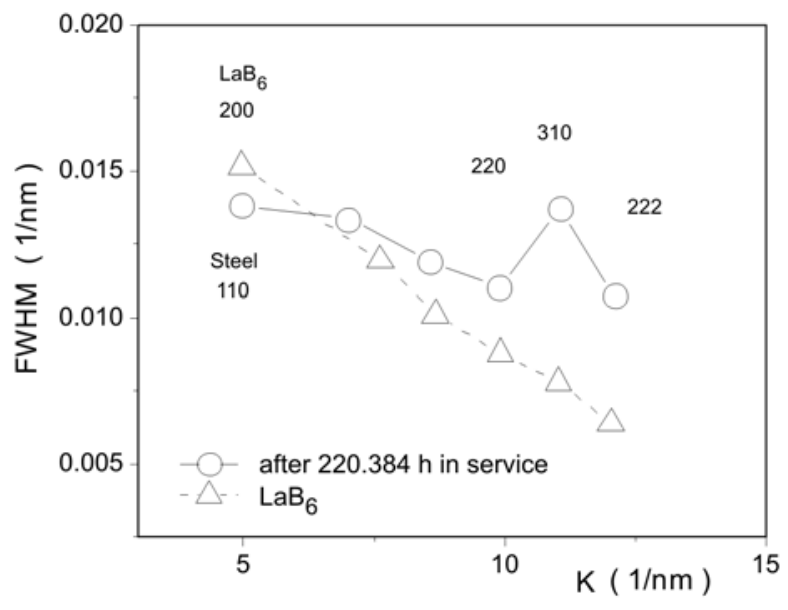

Fig. 2. The FWHM of the $\mathrm{K} \alpha_{1}$ component of the dry-steam pipe material (open circles) and the NIST SRM-660a LaB 6 standard specimen (open triangles) in a Williamson-Hall type plot in $1 / \mathrm{nm}$ scale.

310 reflections as shown on the Imaging-Plate

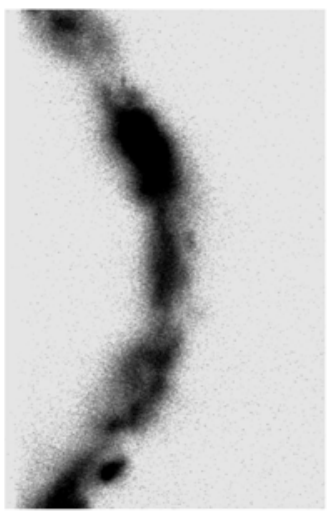

Initial state

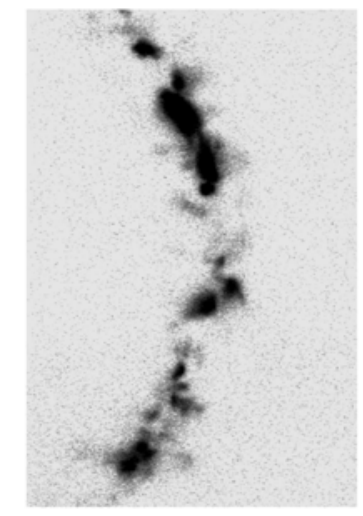

$220.384 \mathrm{~h}$

in service
Fig. 3. Gray scale imaging-plate readouts of the 310 Bragg reflections for the initial state (ISt) specimen and the specimen after $220.384 \mathrm{~h}$ in service.

the steel peaks become much larger than the peaks of the standard specimen. (More details are shown in Figs. 3b,c in [5].) This behaviour indicates that (i) in the steel specimen there is no size broadening, but only strain broadening and (ii) that line profile analysis based on patterns obtained in a conventional $\theta-2 \theta$ diffractometer can be misleading. To overcome this problem a special high resolution double crystal diffractometer dedicated for line profile analysis was applied [6]. A fine-focus Co anode was operated at $35 \mathrm{kV}$ and $30 \mathrm{~mA}$. The symmetrical (220) reflection of a plane Ge monochromator was used to eliminate the $\mathrm{K} \alpha_{2}$ component of Co radiation. The cross section of the 
Table 1. Constitution of the dry-steam-pipe steel materials (wt.\%)

\begin{tabular}{cccccccccc}
\hline $\mathrm{C}$ & $\mathrm{Si}$ & $\mathrm{Mn}$ & $\mathrm{Cr}$ & $\mathrm{Mo}$ & $\mathrm{V}$ & $\mathrm{Cu}$ & $\mathrm{P} \max$ & $\mathrm{S}$ & $\mathrm{Fe}$ \\
\hline $0.08-0.15$ & $0.17-0.37$ & $0.40-0.70$ & $0.90-1.20$ & $0.25-0.35$ & $0.15-0.30$ & 0.20 & 0.025 & 0.025 & Balance to $100 \%$ \\
\hline
\end{tabular}

beam on the specimen was about $0.2 \times 2 \mathrm{~mm}^{2}$. Diffraction patterns were recorded on imaging plates (IP) of $220 \mathrm{~mm}$ long and $100 \mathrm{~mm}$ wide, placed in curved IP holders of $200 \mathrm{~mm}$ radius. Two curved IPs cover the $2 \theta$ angular range from $40^{\circ}$ to about $160^{\circ}$, allowing the measurement of the first 5 reflections from 110 to 310 of the steel specimens.

Transmission electron microscopy (TEM) micrographs were prepared in a $200 \mathrm{kV}$ Jeol 2000 electron microscope. TEM specimens were prepared by the standard double-jet technique in a Tenupol polishing machine. Optical micrographs were made in a standard optical microscope.

\subsection{Evaluation of $X$-ray diffraction patterns}

The diffraction patterns were evaluated by using the convolutional multiple whole profile (CMWP) procedure [9-10]. The measured, $I^{\mathrm{M}}(2 \theta)$ diffraction pattern is matched by the theoretically calculated and convoluted profile functions of the effects of size, $I_{h k l}^{\mathrm{S}}$, distortion, $I_{h k l}^{\mathrm{D}}$, planar defects, $I_{h k l}^{\mathrm{SF}}$ and instrumental effects, $I_{h k l}^{\mathrm{INST}}$, respectively:

$$
I^{\mathrm{M}}(2 \theta)=\sum_{h k l} I_{h k l}^{\mathrm{S}} \times I_{h k l}^{\mathrm{D}} \times I_{h k l}^{\mathrm{SF}} \times I_{h k l}^{\mathrm{INST}}+I_{\mathrm{BG}},
$$

where $I_{\mathrm{BG}}$ is the background determined separately. Since the stacking fault energy in the present steel is relatively large the presence of planar defects was excluded and the $I_{h k l}^{\mathrm{SF}}$ profile functions were not considered. As discussed above, size broadening and the instrumental effects were not considered in the present case. The strain profile is given by its Fourier transform [10]:

$$
\mathrm{FT}\left(I_{h k l}^{\mathrm{D}}\right)=\exp \left\{-2 \pi^{2} L^{2} g^{2}<\varepsilon_{\mathrm{g}, \mathrm{L}}^{2}>\right\},
$$

where $g$ is the absolute value of the diffraction vector and $L$ is the Fourier variable. The mean square strain in dislocated crystals is given by the Wilkens function $f(\eta)$ :

$$
<\varepsilon_{\mathrm{g}, \mathrm{L}}^{2}>\cong \frac{\rho C b^{2}}{4 \pi} f(\eta),
$$

where $\rho$ and $b$ are the density and the Burgers vector of dislocations and $C$ is the dislocation contrast factor. In $f(\eta)$ the variable is: $\eta=L / R_{\mathrm{e}}$ and $R_{\mathrm{e}}$ is the effective outer cut-off radius of dislocations. In a polycrystal or when all possible Burgers vectors are populated the dislocation contrast factors can be averaged over the permutations of hkl, and in cubic system this can be given as [9]:

$$
\bar{C}_{h k l}=\bar{C}_{h 00}\left(1-q H^{2}\right),
$$

where $H^{2}=\left(h^{2} k^{2}+h^{2} l^{2}+k^{2} l^{2}\right) /\left(h^{2}+k^{2}+l^{2}\right)^{2}$, $\bar{C}_{h 00}$ is the average contrast factor of the $h 00$ type reflections and $q$ is a constant depending on the elastic anisotropy of the material and on the edge or screw character of dislocations [9].

\subsection{Specimens}

The chemical composition of the low alloy highstrength and high creep-resistant steel specimens is given in Table 1. One specimen was prepared from the as-received state of the dry-steam pipe: initial-state (ISt). Two further specimens were taken from the tube materials after 154.530 and $220.384 \mathrm{~h}$ in service, respectively. In each state of the materials two specimens were prepared: one from the inner and one from the outer surface region of the $38 \mathrm{~mm}$ wall thickness tube. The initial state was prepared by normalizing from $950-980^{\circ} \mathrm{C}$ and tempered at $720-750^{\circ} \mathrm{C}$, and cooled in air. The operation conditions were at $540^{\circ} \mathrm{C}$ at a pressure of 165 bar. The $10 \times 10 \times 2 \mathrm{~mm}^{3}$ size specimens were cut from the pipe materials by careful forging under cooling liquid. For the sake of removing any damaged surface layer, the specimens were mechanically polished and finally electropolished.

\section{Results and discussion}

\section{1. $X$-ray diffraction patterns}

Two typical gray scale IP readouts of the 310 Bragg reflections for the initial state (ISt) specimen and the specimen after $220.384 \mathrm{~h}$ in service are shown in Fig. 3. The strong spots correspond to individual grains in the specimen. In the previous paper [5] the shifts of the diffraction spots relative to the average Debye-Scherrer arc were evaluated in terms of intergranular stresses. In the present case the peak profiles corresponding to the individual diffraction spots are evaluated in terms of local dislocation densities in different individual grains. The diffraction patterns are "spotty" as it can be seen in Fig. 3. In the case of each Bragg reflection, peak profiles corresponding 

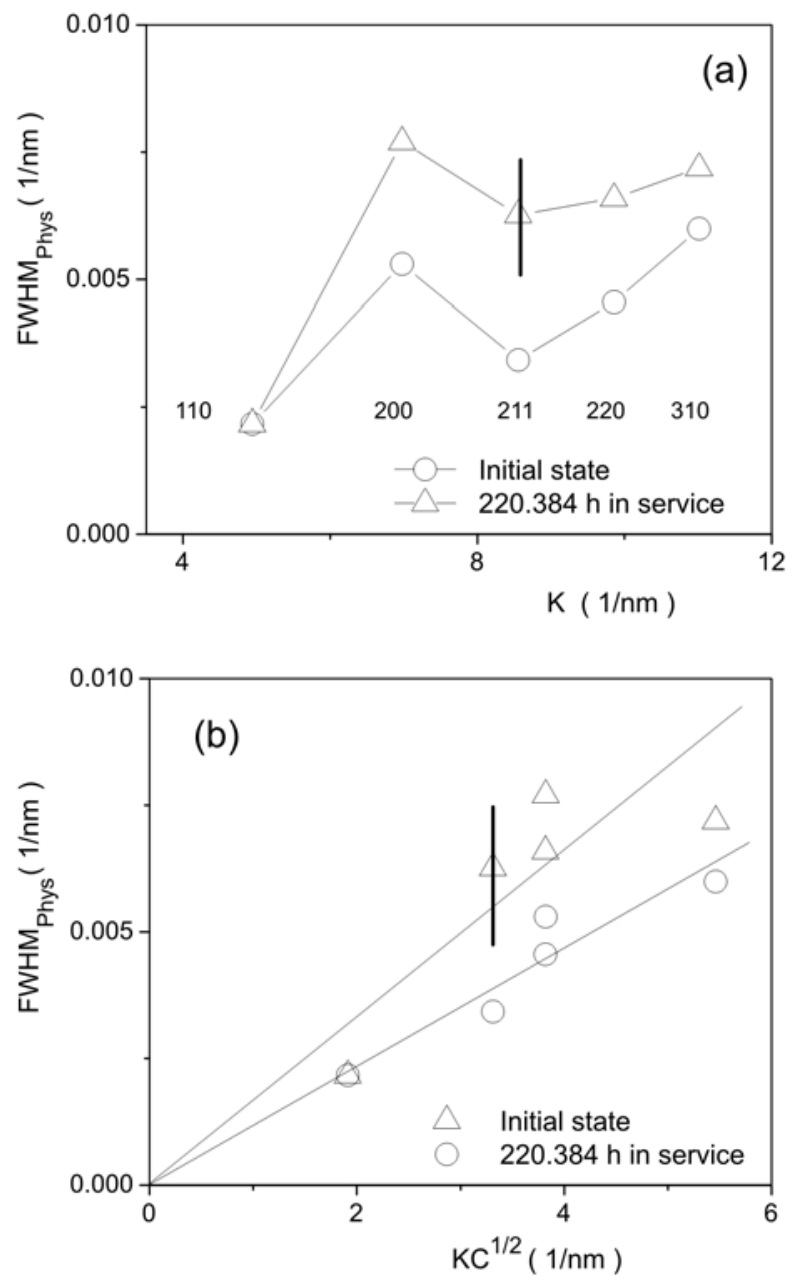

Fig. 4. The Williamson-Hall (a) and modified Williamson-Hall (b) type plots corresponding to the initial state specimen and the specimen after $220.384 \mathrm{~h}$ in service.

to single grains can be determined. The FWHM values corresponding to such single-grain profiles have been determined for several grains in each hkl reflection. The Williamson-Hall type plot corresponding to the initial state specimen and the specimen after $220.384 \mathrm{~h}$ in service in Fig. 4a shows the strain anisotropy typical for bcc crystals [7]. The corresponding modified Williamson-Hall plot [8] is shown in Fig. 4b. The straight lines are linear fits to the FWHM data. For both specimens they intercept the vertical axis at zero, indicating that there is no size broadening contribution in the peak profiles. The offsets of the FWHM values from the straight lines in the modified Williamson-Hall plots are due to the fact that the five different profiles, from which the plots were created, correspond to different grains in which the dislocation densities need not be the same.

A large number of diffraction patterns were constructed by putting together peak profile corresponding to different grains in the "spotty" diffraction pat-

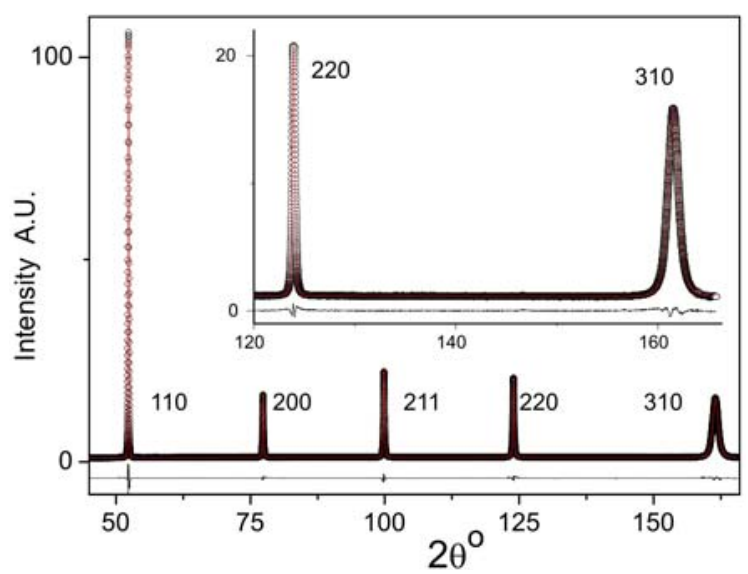

Fig. 5. Typical measured (open circles) and calculated (solid red line) diffraction pattern constructed by putting together peak profile corresponding to different grains in the 'spotty' diffraction patterns. The black line in the bottom of the figure is the difference between the measured and calculated patterns. The inset is an enlarged section of the diffraction pattern.
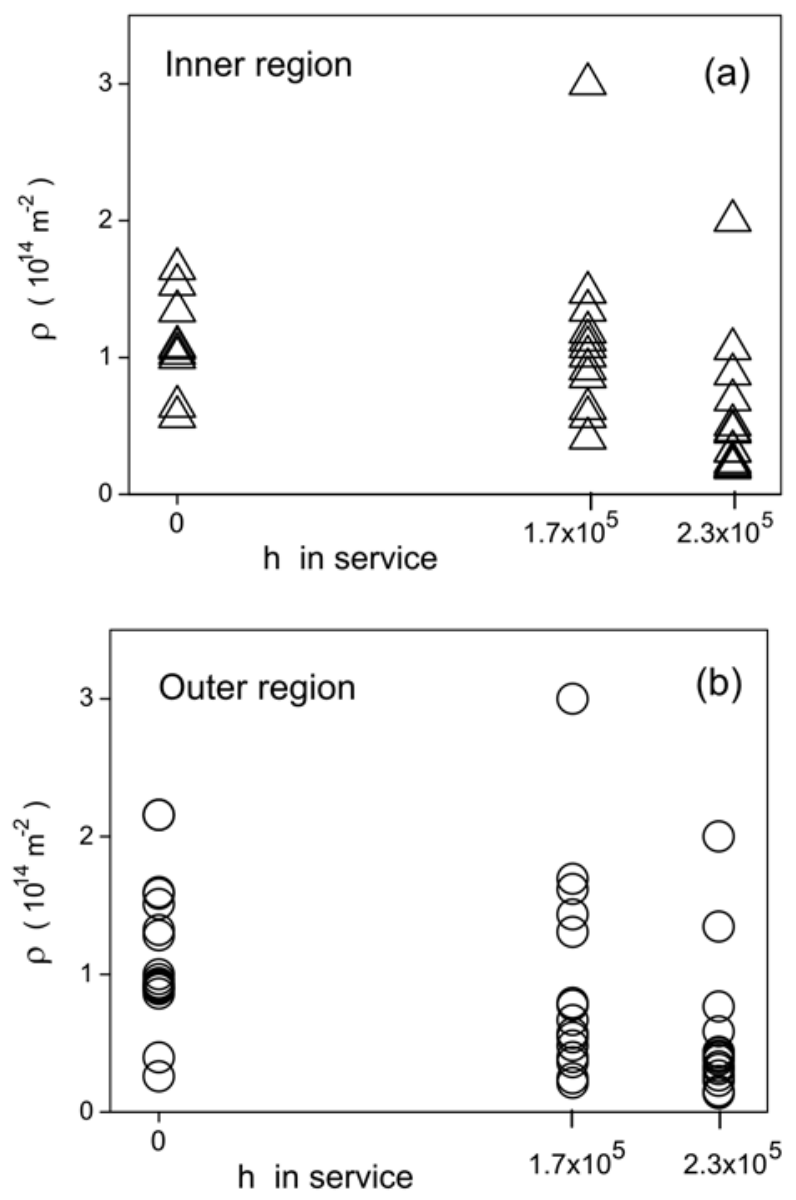

Fig. 6. Dislocation density values for the six different specimens for the inner (a), the outer (b) regions obtained from the diffraction patterns constructed from a large number of different peak profiles. 

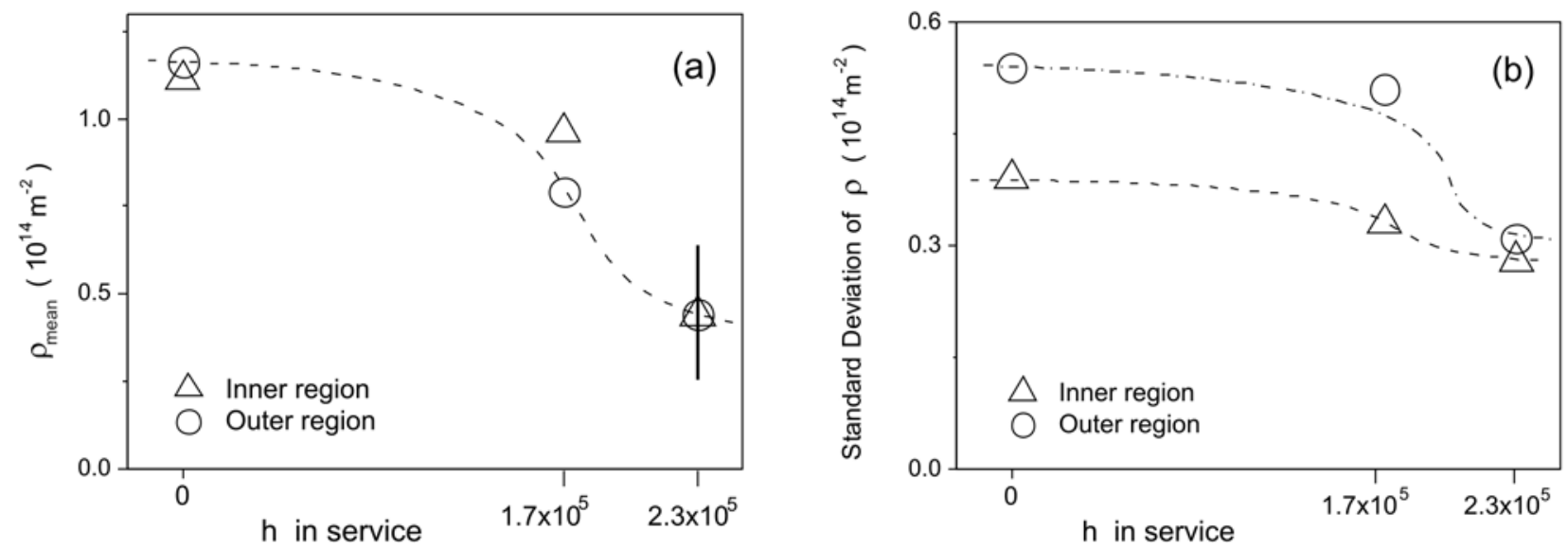

Fig. 7. Mean (a) and the standard deviation (b) values of the dislocation densities in the inner and outer regions of the dry-steam pipe material.

\begin{tabular}{|l|c|c|}
\hline & Inner region & Outer region \\
\hline Initial state & & \\
\end{tabular}

Fig. 8. Optical micrographs in the initial state (a) and after $154.530 \mathrm{~h} \mathrm{(b)}$ and $220.384 \mathrm{~h}$ (c) service period in the inner and outer regions of the tube material, respectively. The horizontal sides of the images are $260 \mu \mathrm{m}$.

terns. One of typical diffraction patterns is shown in Fig. 5. The measured (open circles) and fitted (red line) diffraction patterns indicate very small line broadening. The diffraction patterns were evaluated by the CMWP procedure. The dislocation density values, $\rho$, for the six different specimens are shown in
Fig. 6a for the inner and in Fig. 6b for the outer regions of the dry-steam pipe material. The relatively large scatter in the $\rho$ values, which is far beyond the experimental accuracy, indicates that dislocation densities are very different in different grains. In a recent synchrotron X-ray work [11] the disloca- 
tion density was determined in individual grains in the bulk polycrystalline agglomerate of plastically deformed CoTi and CoZr specimens. It was found that the dislocation density was varying between $5 \times 10^{13}$ and $5 \times 10^{14} \mathrm{~m}^{-2}$ in different individual grains. The means and the standard deviations of the $\rho$ values in the inner and outer regions of the pipe material are shown as a function of service period in Fig. 7. The values in Fig. 7a show that the mean dislocation density drops from about $1.2 \times 10^{14}$ to about $5 \times 10^{13} \mathrm{~m}^{-2}$ indicating a substantial recovery of the dislocation density during the long term service period. In the as received state the standard deviation of $\rho$ is considerably larger in the outer than in the inner regions of the tube which is probably related to the manufacturing procedure. After long terms service also the standard deviation of $\rho$ decreases to lower values and there is no difference between the inner and outer regions in correlation with the recovery process of the dislocation structure.

The optical micrographs in Fig. 8 show that there is no substantial grain growth during the service period neither in the inner nor in the outer regions of the tube material. This means that the major process during long term service is recovery with no grain growth. Typical TEM micrographs for three service time periods are shown in Fig. 9. The micrographs show small carbide precipitates connected by dislocations and/or surrounded by dislocation loops in the inside regions of grains. The grain boundaries contain large carbide particles which become extremely large after long term service as shown in Fig. 9c. The comparison of Figs. 9b and 9c also supports the decrease of the dislocation density with service period.

\section{Conclusions}

The results of the present investigation along with the previous results in [5] are summarized as follows.

1. In the initial state of dry-steam pipe steel materials operating in fossil power plants in Hungary are strain free with relatively low dislocation densities of about $1.2 \times 10^{14} \mathrm{~m}^{-2}$. The good creep resistance of the materials is produced by the evenly dispersed small carbide precipitates pinning the dislocations.

2. During service the dry-steam pipe is thermomechanically loaded by the large operation pressure in the tube and the inevitable cooling and heating of the tube during the operation procedure. The thermomechanical loading procedure produces intergranular strains and stresses, as discussed in detail in [5]. Along with the evolution of intergranular stresses the dislocation density is recovered to a very low value especially after a service period of about 25 years.

3. As discussed in [5] after a service period of about 25 years the intergranular stresses are strongly
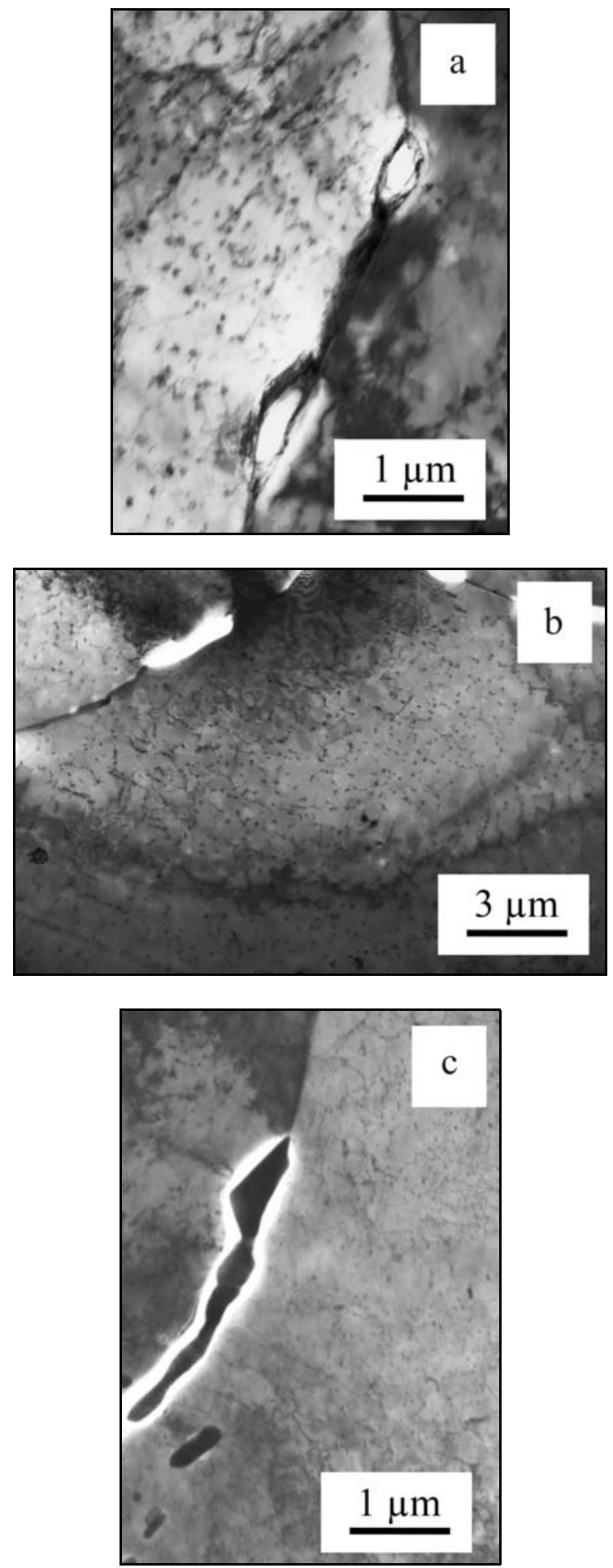

Fig. 9. Typical TEM micrographs in the initial state (a) and after $154.530 \mathrm{~h}$ (b) and $220.384 \mathrm{~h}$ (c) service period.

reduced indicating catastrophic deterioration of the grain boundary structures by coarsening of grain boundary precipitates and void formation. At the same time, the low dislocation density hampers the pipe-line diffusion mechanism and thus retards the 
speed of grain boundary deterioration. The low dislocation density increases the creep resistance property of the material and the life time of dry-steam pipe fabricated from this type of steel.

\section{Acknowledgement}

This paper is dedicated to the 80th birthday of Professor Pavel Lukáč.

\section{References}

[1] Paterson, I. R., Wilson, J. D.: Int. J. Pressure Vessels Piping, 79, 2002, p. 541. doi:10.1016/S0308-0161(02)00094-7

[2] Singh, R., Singh, S. R.: Int. J. Pressure Vessels Piping, 73, 1997, p. 89. doi:10.1016/S0308-0161(97)00038-0

[3] Suna, W., Hyde, T. H., Becker, A. A., Williams, J. A.: Int. J. Pressure Vessels Piping, 77, 2000, p. 389. doi:10.1016/S0308-0161(00)00044-2
[4] Sklenička, V., Kuchařová, K., Svoboda, M., Kloc, L., Buršík, J., Kroupa, A.: Mater. Characterization, 51, 2003, p. 35.doi:10.1016/j.matchar.2003.09.012

[5] Gémes, G., Balogh, L., Ungár, T.: Kovove Mater., 48, 2010, p. 33.

[6] Ungár, T., Ott, S., Sanders, P. G., Borbély, A., Weertman, J. R.: Acta Mater., 46, 1998, p. 3693. doi:10.1016/S1359-6454(98)00001-9

[7] Shen, T. D., Schwarz, R. B., Thompson, J. D.: Phys. Rev. B, 72, 2005, p. 014431. doi:10.1103/PhysRevB.72.014431

[8] Ungár, T., Borbély, A.: Appl. Phys. Lett., 69, 1996, p. 3173. doi:10.1063/1.117951

[9] Ungár, T., Dragomir, I., Révész, Á., Borbély, A.: J. Appl. Cryst., 32, 1999, p. 992. doi:10.1107/S0021889899009334

[10] Ribárik, G., Ungár, T.: Mater. Sci. Eng. A, 528, 2010, p. 112. doi:10.1016/j.msea.2010.08.059

[11] Ungár, T., Ribárik, G., Zilahi, Gy., Mulay, R., Lienert, U., Balogh, L., Agnew, S.: Acta Mater., 71, 2014, p. 264. doi:10.1016/j.actamat.2014.03.024 